\title{
The Study on the Reform and Development of Primary Mathematics Teaching Material in a New Era
}

\author{
Yong Wang \\ Linyi University (Feixian Campus) \\ Linyi, China 273400
}

\begin{abstract}
Based on the revolution of primary mathematics teaching material in China, this article summarizes and analyzes the problems existed in teaching material construction, and it combines the related policies with the models and experience of teaching material construction given in different areas, which not only gives the realistic significance on the current understanding of the basic education reform, especially the reform of primary and junior school mathematics textbooks, but also has the important enlightenment to the future reform trend of the primary mathematics textbooks. Meanwhile, it is also helpful to inherit the tradition of excellence, innovation and development of the primary mathematics teaching materials.
\end{abstract}

Keywords-textbook construction; evolution; problems; suggestions

\section{INTRODUCTION}

Since the implement of the reform and opening-up policy, an increasingly independent, distinctive and refined textbook-constructing system with much improvement on the selection of contents and their arrangements has been established after the thirty-year evolution of construction of the math textbooks for primary schools. However, there is no doubt that some problems and challenges are still in existence. Therefore, some existing problems and concerning policies would be explored on the basis of the evolution and reform of the math textbook construction, aiming at a better implementing of the related guidelines and policies and a light-shedding on further textbook construction.

\section{EVOLUTION OF THE CONSTRUCTION OF MATH TEXTBOOKS FOR PRIMARY SCHOOLS}

In the year of 1977, after the Period of Bring Order out of Chaos, the Chinese Ministry of Education summoned a national conference on the compilation of textbooks in primary and secondary schools, aiming at compiling the new teaching programs and new textbooks. In February 1978, Chinese Ministry of Education issued the Math Teaching Programs for Full-time Ten-year Primary Schools (Pilot Draft), and the course title of "Arithmetic" was renamed "Math". In the autumn of the same year, the Math Textbook for Full-time Ten-year Primary Schools Book One (Trial Edition) compiled by People's Education Press was published and was used nationally, starting a new phase of reform in math textbooks for primary schools. On April 12th
1986, the Compulsory Education Law of the People's Republic of China was promulgated, legally identifying the goal of realizing the national popularization of nine-year compulsory education in the 1990s. In the same year, the State Education Commission issued Math Teaching Programs for Full-time Primary Schools, which was a trial program for the implementing of the compulsory education, demonstrating the transformation from an exam-oriented education to a quality-oriented one. In the autumn of the same year, the Pilot Math Textbook for Primary Schools compiled by the Math Branch of People's Education Press was published. Meanwhile, as a measurement to standardize the construction of textbooks, State Education Council established National Textbook Examining and Approving Committee for Primary and Secondary Schools, normalizing the construction of textbooks. In May 1988, State Education Council decided to compile various kinds of textbooks respectively applicable to different length of schooling, regions and levels in the conference on textbook compiling for nine-year compulsory education schools. In June 1992, State Education Council publicized the Math Teaching Programs for Nine-year Compulsory Education Full-time Primary Schools (Trial Edition). Consequently, the original textbook was revised by the People's Education Press and approved by the Textbook Examining and Approving Committee of State Education Council, serving as one of the options for national urban and rural primary schools implementing compulsory education in the autumn of 1993. In March 2000, the programs issued in 1992 was revised and the Math Teaching Programs for Nine-year Compulsory Education Full-time Primary Schools (Revised Trial Edition) was issued, with all the versions of textbooks revised and the situation of one single universal version dominance broken completely. Following the worldwide trend of curriculum reform, China formulized its brand-new Math Curriculum Standards for Full-time Compulsory Education, an embodiment of the popularization, elementariness and expandability of compulsory education. In April 2001, guided by the notion of new curriculum reform, many presses published various kinds of pilot new math textbooks, starting a new phase of "One Standard, Various Textbook". 


\section{PROBLEMS IN THE CONSTRUCTION OF MATH TEXTBOOKS FOR PRIMARY SCHOOLS}

\section{A. Special Features to be Enhanced}

At present, two problems are prominent regarding the features of textbooks. One the one hand, the exploration of specific features needs further refining. To meet the needs, it is necessary for the textbooks to adapt themselves to the regional customs and social consciousness of various kinds of specific areas. Furthermore, the compiling features of the contents should be strengthened. The current approaches to demonstrating the features still focus on the first aspect, with little attention on the second aspect. On the other hand, the demonstrating approaches to the features are superficial. To use the special features as one of the factors of problem situations, with their positioning in the exercises section, resulting in single-category content and a low demonstrating frequency.

\section{B. The Systematicness of Knowledge to Be Improved}

Some compiling approaches probably do great damage to the systemsticness of knowledge, leading to the disorder in the knowledge hierarchy. To take the knowledge of "angle": the components of the angle and the category of right angel is introduced in Unit Three, Book One, Grade Two; Other categories, namely, acute angel and obtuse angle, are introduced in Unit Three, Book Two, Grade Two, but only in a preliminary way; While the systematic study of the measurement and category of angles was introduced in Unit Two, Book One, Grade Four. This scattered compiling approach makes it difficult for the pupils to have a systematic command of the knowledge. Therefore, integrating them into one book or one grade would be a better choice.

The section of "The Rudimentary Knowledge of Decimal Fraction", in Unit Seven, Book Two, Grade Three, involves the comparison of the values of decimal fraction and simple addition and subtraction of decimal fraction. The acquisition of such knowledge should be based on the knowledge of the calculating unit and numerical digit of decimal fraction, which would be dealt with in the section of "Significance and Nature of Decimal Fraction" in Unit Four, Book Two, Grade Four. Therefore, it is suggested to adjust the order or combine these two sections, enabling students to have a logical and systematic command of the knowledge of decimal fraction.

\section{Some Knowledge to Be Specified}

The section of "The Combination of Figures" in the math textbook of Book One, Grade One compiled by Jiangsu Education Publishing House involves the three-dimensional figures, and is difficult to understand because its abstraction; While in the section of "Right and Left" in the same book, it is even difficult for teachers to determine the specific position of the figure in the picture.

The section of "Parallel Translation and Rotation" is difficult to comprehend, and it is suggested to rearrange the section in a due part in Grade Three or Grade Four. In Book
Four compiled by Jiangsu Education Publishing House, the first unit involves "problem-solving", with the sections of comprehensive employing of addition and subtraction to conduct two-step calculation and learning to use round brackets. It is obviously demanding to the pupils in Grade Two in that the combined using of the comprehensive calculation and the round bracket is generally taxing for the pupils.

\section{Some Questions to Be Clarified}

- The "application-oriented questions" section is replaced by the "problem-solving" section, which is scattered in different chapters and sections, with varied forms. Moreover, some are greatly informative and the answers are usually more than one, many possibilities involved. It not only is mentally demanding for the pupils, but poses great pressure to the teachers. For instance, Question No.3 on Page 35 and Question No.4 on Page 36 in Book Two, Grade Two.

- There is no universal standard for rough calculation in the textbook, therefore, it is difficult for teachers to evaluate the strategies adopted by the pupils. For instance, Example No. 5 on Page 98 in Unit Seven, Book Two, Grade Two.

- The logical sequence of the compiling of contents is unreasonable to some degree. It is widely acknowledged that to follow the logical sequence of the textbook to teach would make the students confused. The transition from the previous section to the next one is abrupt, without adequate training and digestion. Consequently, it is suggested that the new contents should be introduced after students' adequate digestion and thorough comprehension.

\section{SOME SUGGESTIONS ON THE CONSTRUCTION OF MATH TEXTBOOKS FOR PRIMARY SCHOOLS}

As a cardinal course, math plays an important role in primary school education. Significant reforms have been made in the construction of math textbooks, with the textbooks more real-life-oriented, serving as a tool to foster the students' capability of logic thinking, innovation and problem-solving. Despite all the advantages, further refinement is still required to enhance the compiling quality and provide support for the math learning and teaching.

\section{A. Incorporating the Knowledge into the Real Life in a Better Way}

With the course of math being a preliminary course, math textbooks for primary schools mainly deal with the brief introduction of some basic knowledge, while the math course is also practical in that it helps to solve problems in actual life. The purpose of teaching can only be achieved by applying the knowledge of math to the actual life. Given its practical function in the daily life, the compiling of the math textbook should be combined with the problem-solving in real life, thus stimulating students' interest and initiative. As the new curriculum reform is pushed ahead, the problem- 
solving capability in actual life is becoming increasingly important, and the introduction of relevant knowledge into the textbooks can enhance the capability.

\section{B. Making the Integrity of Knowledge More Prominent}

In compiling the math textbooks, the integrating of interdisciplinary knowledge should be given much priority in that the math knowledge is closely associated with the knowledge of other disciplines. It can be applied in the problem-solving in other disciplines and facilitating the learning of them. Therefore, in the compiling process, paying due attention to the connections between math and other disciplines would be of great benefit to the learning of both math knowledge and knowledge of other disciplines.

\section{Adding Practice-oriented Activities}

New curriculum reform requires the students to participate in more practice-oriented activities. The math knowledge, to some extent, is related with the practiceoriented activities. And the learning of the math knowledge is to solve the problems in actual life. However, in math textbooks, the trainings connected with such kinds of activities or with operational capability are inadequate. Therefore, some practice-oriented activities should be added to promote the operational capability in the text compiling. It is required by the new curriculum that the students' innovative and operational capabilities should be enhanced. The addition of such kinds of activities in the math textbook meet the requirements both in theory and practice.

\section{CONCLUSION}

As a preliminary course, math in primary schools plays a key role in students' learning. The compiling rules of math textbooks should be conformed to the requirements of the new curriculum reform, especially the goal of enhancing the students' innovative and operational capabilities. Therefore, the compiling notions for math textbooks should be transformed from being teacher-oriented to student-oriented, adopting vivid and lively languages to reveal the mathspecific thinking modes and enhancing the readability of textbooks. In some sense, further efforts are to be made in this respect.
[5] Liu Juan-juan. Reflection on the Development of the Textbook for Primary School Teaching Theory of Math[M]. Journal of Hunan First Normal College,Sep.2008.

\section{REFERENCES}

[1] Li Xing-yun. Review and Reflections on the Construction of Primary School Mathematics Textbooks over the Three Decades of Reform and Opening-up[M]. Curriculum, Teaching Material and Method,January,2010.

[2] Tan Xiao-jun. On Mathematics Textbook Diversified Construction of Chinese Primary School[M]. Journal of Southwest China Normal University (Natural Science Edition),Jun.2014.

[3] Zheng Yu-xin. Some Thoughts on the Construction of Mathematics Teaching Materials for Primary School[M]. Curriculum, Teaching Material and Method. July,2006.

[4] Pu Shu-ping, Song Naiqing. Research on International Development Trends of Primary Mathematics Textbooks in the 21st Century Based on the 12 Sets of Primary School Textbooks from 10 Countries[M]. Educational Research,No.5,2017 